\section{Astrup, Poul}

O. Müller-Plathe

Hamburg, Deutschland

Lebensdaten Dänischer Physiologe und Laborarzt, geboren am 4. August 1915, gestorben am 30. November 2000 in Kopenhagen.

Verdienste Professor für Klinische Chemie in Kopenhagen. Er entwickelte Methoden der Blutgas- und Säure-Basen-
Analytik ( $\triangleright$ Säure-Basen-Stoffwechsel) sowie in Zusammenarbeit mit der Firma Radiometer den ersten kompakten Blutgasanalysator ( $\triangleright$ Blutgasanalyse). Astrup wurde im Jahr 1981 mit der Scherer-Medaille der Deutschen Gesellschaft für Klinische Chemie ausgezeichnet.

\section{Literatur}

Siggaard-Andersen O, Engel K, Jorgensen K, Astrup P (1960) A micro method for the determination of $\mathrm{pH}$, carbon dioxide tension, base excess and standard bicarbonate in capillary blood. Scand J Clin Lab Invest 12:172-176 